\title{
Institutes unite to put New York on the biopharma map
}

New York is known for doing everything big, with its soaring skyscrapers, throngs of people and huge pizza slices. But the Big Apple has not traditionally been such a big hub for the biopharma industry compared with other places such as San Diego or Boston. The city has tried to remedy that by investing around \$26 million dollars in recent years to build or renovate office and lab spaces for life sciences ventures in Manhattan and Brooklyn. But some experts think that the mayoral efforts will not bear fruit until the city's scientific community gets behind them.

Now, New York's research institutions have joined the city in an effort to jumpstart biopharma. On 3 November, scientists, investors, and government officials announced the formation of the New York Genome Center (NYGC), a \$125 million core facility funded by the city, private groups and 11 founding institutions-all based in the New York area except for the Jackson Laboratory of Bar Harbor, Maine. The new center is slated to open its doors at the end of 2012.

"The hope is that, with the support of the city and the center bringing together all the universities in a collaborative way, there will be a new atmosphere to draw new companies to the city," says Tom Maniatis, head of biochemistry and molecular biophysics at the Columbia University Medical Center and chair of the NYGC's scientific advisory board.

New York's failure to generate a cluster of biotech startup companies to match its financial prowess has puzzled economists and researchers for decades. There is plenty of innovation at the many world-class universities and research hospitals that call New York home, not to mention money from Wall Street to drive product commercialization. Nonetheless, most discoveries made in the city are exported to other parts of the country. "In New York, we lose four out of five biotech companies, and that's a shame on all of us," says Maggie Moree, director of federal affairs at the Business Council of New York State, based in Albany. "They're not going far, and now we have to figure out why."

Experts blame the city's dearth of lab space and high real-estate costs for its biopharma brain drain. But those problems are subsiding with the completion of new development projects such as the $\$ 700$ million Alexandria Center for Life Science-opened in 2010 and now fully leased with big pharma, biotech and nonprofit tenants-and the cheaper Brooklynbased BioBAT incubator space.

The lack of local biotech investment is another oft-cited dilemma, with venture funding down threefold between 2008 and 2010 , from more than $\$ 225$ million to $\$ 80$ million, according to an October report from the New York Biotechnology Association. But recent efforts, such as the formation of the New York Health Business Leaders in 2009 and the New York Academy of Sciences's Life Sciences Angel Network, which launched last year, aim to forge relationships between venture capitalists and entrepreneurs to turn that investment trend around.

\section{Start spreading the news}

The more elusive problem, says Moree, is that New York lacks a vibrant community of scientists working in the biopharma sector from which to develop and attract talent. The new genome center, however, should help bring skilled researchers into the city. Within five years of opening at an undetermined location (see 'Genome center's location stuck in transit'), the NYGC will house more than 100 sequencing machines, provided at a discount by Illumina of San Diego, and hire 550 employees. These will include 180 bioinformatics specialists, who will help with sequencing projects and data analysis for investigators at any New York institution.

This shared investment in equipment and technology should go a long way toward fostering a new workforce and keeping the city competitive, according to Thomas Kelly, director of the Sloan-Kettering Institute. "Everyone saw that there was tremendous advantage in trying to come together and achieve some economies of scale rather than try to build all this expensive infrastructure at each individual institution," he says.

The founding consortium has no requirements that discoveries coming out the NYGC stay in the city. So only time will tell whether the new center, combined with the city's real-estate endeavors, can create enough momentum to make New York a biotech hotspot. But the collaborative spirit exemplified by the NYGC is the model for generating the entrepreneurial communities seen in other cities, notes Michael Eckstut, head of life sciences at Archstone Consulting in San Francisco. "It's very much of a network kind of model where success breeds success," he says. "It takes a bit of time to get that critical mass, so you have to have a little bit of patience."

Hannah Waters

\section{Genome center's location stuck in transit}

Yankees-Mets. Giants-Jets. These are the sorts of things that usually divide New Yorkers. But beyond sports rivalries, a rift has formed among the founding members of the New York Genome Center (NYGC) about where to locate the new facility.

Three of the consortium's ten New York area members are on Long Island, including the Cold Spring Harbor Laboratory and Stony Brook University. But because the NYGC has mayoral funding, the center is required to break ground within city limits. This could include the outer boroughs, but "we're very interested in keeping this in Manhattan, because we think it's important to have the city institutions nearby," says NYGC executive director Nancy Kelley.

Nearly all of the Manhattan-based members of the consortium are on the Upper East Side of the city, including Rockefeller University, Weill Cornell Medical College and Mount Sinai Medical Center. But, after looking at more than 100 sites across Manhattan and visiting more than 40 of them, the search did not turn up a potential site in this affluent neighborhood. Instead, the NYGC steering committee narrowed the search down to just two finalists: one in the Hell's Kitchen area west of Times Square, and the other down in TriBeCa just north of the financial district.

Ultimately, the decision might boil down to subway access, as navigating Manhattan east to west is notoriously difficult with public transit. "The ideal location, in my view, would be TriBeCa, because all of the subway lines converge there," says Columbia University Medical Center's Tom Maniatis, who will chair the NYGC's scientific advisory board. "With the subway, you can imagine that even though the Genome Center is located in [Manhattan] for convenience, you could be connected to biotech parks in other boroughs." - HW

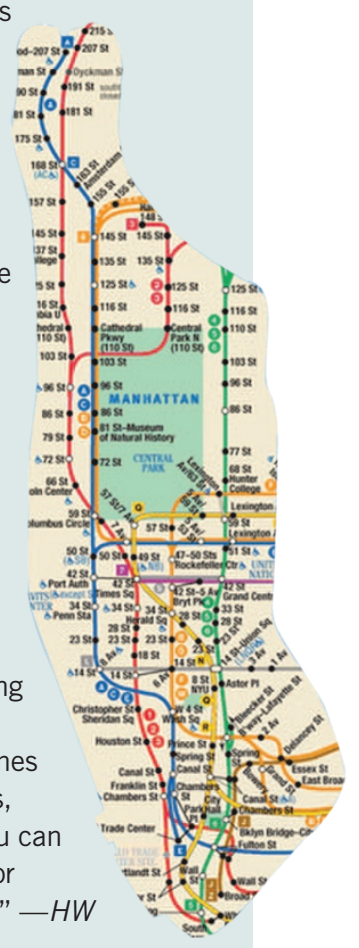

